Viso - Cadernos de estética aplicada Revista eletrônica de estética

ISSN 1981-4062

No 17, jul-dez/2015

http://www.revistaviso.com.br/

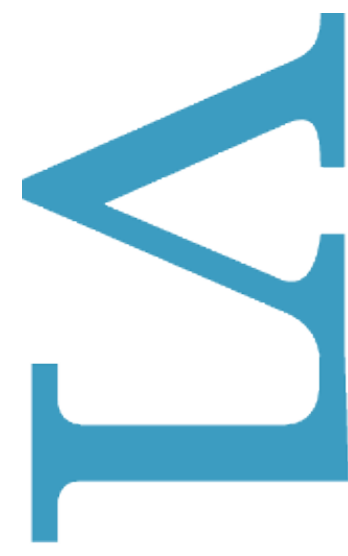

\title{
Deslocamentos e deformações em Kafka Jeanne-Marie Gagnebin
}

Pontifícia Universidade Católica de São Paulo (PUC-SP) 


\section{RESUMO}

\section{Deslocamentos e deformações em Kafka}

Esse artigo tenta refletir sobre o questionamento do sentido que a prosa de Kafka opera, forçando o leitor a outra atitude em relação ao texto. Apoia-se, em particular, nos ecos da interpretação de Max Brod (na sua biografia de Kafka) nos textos, críticos, de Günter Anders, Walter Benjamin e Theodor W. Adorno.

Palavras-chave: Kafka - deformação (“Entstellung”) - judaísmo - alegoria - sentido

\section{RESUMÉ}

\section{Déplacements et déformations chez Kafka}

Cet article essaie de réfléchir sur le questionnement du sens qu'opère la prose de Kafka, obligeant le lecteur à une autre attitude vis-à-vis du texte. II s'appuie, en particulier, sur les échos de l'interprétation de Max Brod (dans sa biographie de Kafka) dans les textes, critiques, de Günter Anders, Walter Benjamin et Theodor W. Adorno.

Keywords: Kafka - déformation ("Entstellung") - judaïsme - allégorie - sens 
GAGNEBIN, J.-M. "Deslocamentos e deformações em Kafka". In: Viso: Cadernos de estética aplicada, v. IX, n. 17 (jul-dez/2015), pp. 1-14.

DOI: 10.22409/1981-4062/v17i/202

Aprovado: 07.11.2015. Publicado: 27.02.2016.

(C) 2016 Jeanne-Marie Gagnebin. Esse documento é distribuído nos termos da licença Creative Commons Atribuição-NãoComercial 4.0 Internacional (CC-BY-NC), que permite, exceto para fins comerciais, copiar e redistribuir o material em qualquer formato ou meio, bem como remixá-lo, transformá-lo ou criar a partir dele, desde que seja dado o devido crédito e indicada a licença sob a qual ele foi originalmente publicado.

Licença: http://creativecommons.org/licenses/by-nc/4.0/deed.pt BR

Accepted: 07.11.2015. Published: 27.02.2015.

(C) 2016 Jeanne-Marie Gagnebin. This document is distributed under the terms of a Creative Commons Attribution-NonCommercial 4.0 International license (CC-BY-NC) which allows, except for commercial purposes, to copy and redistribute the material in any medium or format and to remix, transform, and build upon the material, provided the original work is properly cited and states its license.

License: http://creativecommons.org/licenses/by-nc/4.0/ 
A proposta desse texto é uma tentativa de ler um pequeno texto de Kafka, um dos mais enigmáticos, e de ajudar, com o auxílio de vários comentadores, entre outros, Adorno e Benjamin, a nele ouvir um deslocamento simultaneamente radical e discreto. Deslocamento sobre a questão da forma, do sentido sobre a operação da leitura em nossos hábitos de interpretar o sentido: o sentido do texto, o sentido do mundo.

Esse exercício repousa sobre uma premissa heurística, a saber, que os textos literários são comparáveis a sismógrafos de nossa sensibilidade: eles anunciam o terremoto por vir sem com isso indicar como nos salvar da catástrofe iminente. Tomo emprestada a imagem do sismógrafo a Paul Ricoeur e ressalto que esse filósofo foi um dos poucos pensadores contemporâneos que souberam prestar homenagem à literatura ${ }^{1}$, à ficção, naquilo que comporta de metafísico no bom sentido do termo, isto é, uma interrogação sobre os limites da existência e do conhecimento humanos, sobre o enigma desses limites [Grenzen] que escapam à razão e, ao mesmo tempo, a definem. Adorno e Benjamin também leem os textos literários desta maneira interrogativa, que questiona a vontade de ordenamento e compreensão do pensamento humano, essa vontade ou esse furor taxinômico com o qual se confunde, tantas vezes, a atividade do pensamento filosófico.

Ora, ao lado da obra de Beckett, os textos de Kafka são, sem dúvida, aqueles que mais encantam e também irritam o leitor, estimulam sua vontade de interpretação e compreensão. Às vezes, aliás, essa obra somente irrita, em particular o leitor filósofo, mesmo simpático e sensível, mas que se desespera com a opacidade desses textos tão transparentes. Ler Kafka consiste, pois, em primeiro lugar, em deixar ir à deriva nossa busca de significações. Lemos textos coerentes, bem construídos, recheados de figuras argumentativas que parecem lógicas, escritos num vocabulário banal e cotidiano - e não entendemos o que eles "querem dizer", o que significam.

Esse mal-estar é tão antigo como a produção mesma de Kafka (cuja "significação" nem podemos pressupor que o próprio Kafka "entendia"). Essa sensação de admiração e de perplexidade norteia a primeira interpretação de conjunto da obra, a leitura de Max Brod, amigo de juventude e de maturidade, um amigo muito próximo - já que é difícil dizer "íntimo" quando se trata de Kafka. Max Brod se apoia nessa proximidade para escrever a primeira grande biografia do escritor, publicada em 1937. Ressalto a importância desse livro porque ele fornece a base de muitos comentários posteriores, mesmo que fundamentalmente críticos, como os de Günter Anders, de Walter Benjamin ou de Adorno, proporcionando-Ihes o substrato onipresente, mesmo que não citado de maneira explícita.

Como se sabe, Max Brod fazia parte do círculo de jovens escritores judeus e tchecos de língua alemã, ligados ao expressionismo literário, círculo frequentado por Kafka. Também foi um representante ativo da corrente de renovação do judaísmo tradicional e se tornou um sionista declarado, emigrando para a Palestina em 1939. Esse seu sionismo será o 
ponto de maior discordância com o amigo. Brod o reconhece e cita, com honestidade, uma observação do diário de Kafka, datada de novembro de 1913, uma época na qual ele confessa o ter "atormentado" [quälen] com seu proselitismo sionista e sua ideia de "educação para a comunidade". ${ }^{2}$ Kafka anota no seu diário:

Anteontem de noite na casa de Max. Ele se torna cada vez mais estranho, ele já o era para mim muitas vezes, agora eu também o estou ficando para ele. 'O que tenho em comum com judeus?' Tenho por pouco algo comum comigo e deveria me colocar totalmente silencioso num canto, satisfeito com o fato que posso respirar. ${ }^{3}$

Essa anotação aponta para a temática, tão presente em Kafka, da estranheza, da "estrangeirice", em relação a seu "povo", sem dúvida, os judeus, mas também em relação a si mesmo, a seu próprio corpo, a seu próprio ser. Aponta igualmente para outra tendência possível, que Günter Anders denuncia: uma alienação sinônima de um retirarse mudo num canto, uma certa passividade resignada, diz Anders, um niilismo típico das vanguardas, dirá Lukács.

Mas de volta a Max Brod. Ele não desiste de incluir seu amigo renitente na grande obra comunitária e o conseguirá quando interpreta os últimos anos de Kafka em Berlim, morando com Dora Diamant, uma jovem educadora judia. Brod chega a falar da felicidade de pater familias ${ }^{4}$ de Kafka e celebra, no mesmo embalo, a situação conjugal enfim bem sucedida de Kafka e a comunidade sionista, já que Dora e Kafka evocaram, algumas vezes, deixar a Berlim miserável do pós-guerra e emigrar para a Palestina onde poderiam montar um pequeno restaurante: Dora era uma exímia cozinheira, Kafka se imaginava como garçom! Ora, o mesmo Brod relata na sua biografia que o pai de Dora, preocupado com o relacionamento de sua filha, vinte anos mais jovem que o escritor, teria consultado um rabino a respeito de uma eventualidade de casamento, e que foi fortemente desaconselhado por este a autorizar tal casamento. Todas essas anedotas paradoxais ilustram o esforço de Max Brod (não será o único) para tentar encerrar a vida e a obra de Kafka numa operação de salvação e de enclausuramento, operação que casamento e religião (no caso, redobrada pelo sionismo) representam por excelência. Brod tenta a qualquer custo encerrar a personalidade de seu amigo - um homem sensível, hesitante, indeciso, talvez até covarde, tão conformista como ferozmente inconformista (coitada da 'noiva' Felice!), um homem com problemas de saúde e de ordem sexual, enfim um homem estranho como nós todos - como também sua obra, grande, inacabada e incomum, dentro de uma única interpretação abrangente que conseguiria explicar tudo: as esquisitices (eufemismo) de Franz e as lacunas abissais sobre as quais seus textos se equilibram. A tese principal do livro, tese afirmada contra as leituras pessimistas e existencialistas do período, consiste assim, em afirmar que

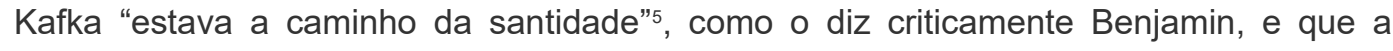
relação com o Sagrado sustentaria sua obra.

Deve-se observar que Brod oscila entre dois conceitos dos termos religião e religioso, escolhendo o que mais the convém dependendo do contexto. Numa primeira acepção, 
"religião" aponta para um ideal de sentido integrador que permite construir uma vida humana comunitária, uma união com os outros, membros da mesma comunidade (judaica ou sionista), uma vida preenchida por um trabalho satisfatório e uma realização conjugal e familiar feliz; numa segunda acepção, "religião" significa a presença de uma dimensão de transcendência, incomensurável a nossas representações e a nossa linguagem comuns, uma dimensão fundadora, mesmo que escondida, e que deve ser procurada e reconhecida. Essa amplidão do conceito de "religião" permite a Brod dar uma explicação totalizante da vida e da obra do seu amigo. Movido por um desejo de uma vida afetiva e profissional mais autêntica, por uma saudade de comunidade verdadeira, Kafka teria criado textos literários de alto teor simbólico que sempre apontariam para uma realidade transcendente maior: assim, o Processo seria o símbolo do Juízo, o Castelo do Castigo e América da Graça divinos, símbolos que tornam explícita a busca espiritual de Kafka. Benjamin deverá observar, na sua crítica à biografia de Brod $^{6}$, que ele nem concede a essas obras o estatuto mais interrogativo da comparação alegórica, preferindo afirmar seu caráter simbólico, isto é, de uma relação imediata com a transcendência e com o universal. De fato, as categorias de símbolo (de sym-ballein em grego, lançar junto) e de comunidade (com-mum) ressaltam, ambas, a possibilidade de conjunção do sentido ou do grupo. Ambas destacam uma plenitude linguística e existencial que permite apagar as fissuras e as rachaduras tanto da vida quanto da obra em prol da afirmação de um sentido transcendente que a vida deveria testemunhar e que a literatura teria por missão configurar.

O livro muito mais conhecido entre nós, Kafka. Pro \& Contra, de Günter Anders ${ }^{7}$, rebate a interpretação de Brod a partir de uma posição marxista assumida. Brod bem o entendeu e publicou em resposta uma resenha aniquiladora do livro de Anders, resenha intitulada "Ermorderung einer Puppe namens Franz Kafkas", na qual defende sua visão positiva e religiosa contra a "boneca" passiva e pré-fascista montada pelo crítico marxista. De fato, o livro de Anders não é somente uma análise fina dos processos de deslocamento (ou de "desloucamento" como Carone traduz a palavra Verrückung), de deformação e de alienação na obra de Kafka; ele contém também uma crítica cerrada da ambiguidade literária desta obra. Segundo Anders, mesmo que denuncie a "loucura" da normalidade, a obra de Kafka falha em não conseguir esboçar estratégias de transformação dessa realidade; ela irradiaria mesmo um misto de obediência e de conformidade, um negativismo desesperado que desaguaria na justificação da autoridade. Faltaria à obra de Kafka um conceito positivo de liberdade e, por isso, ela ficaria presa numa mera celebração da angústia, desembocando num apelo "pré-fascista" a uma autêntica "Führerschaft" ou liderança. Escreve Anders:

Não se pode negar, por outro lado, que sua sede de 'pertinência' total desabafou, algumas vezes, como arrazoado de defesa da desindividualização e da dependência: 'Unidade, unidade!', consta em 'Durante a construção da Muralha da China', 'peito unido ao peito do próprio povo, o sangue não mais retido na escassa circulação do corpo, mas rolando suavemente e no entanto retornando pela China infinita'. Ou: 'Outrora era lema secreto de muitos e até dos melhores: procure entender com todas as suas forças as 
disposições da liderança, mas até um certo limite, depois deixe de pensar. Um lema muito sensato.'

Quem hoje lê desprevenidamente essas frases tem que considerá-las, em vista dos vocábulos de organologia, um documento literário pré-fascista - um discurso de defesa da obediência cadavérica e do sacrificium intellectus. Na realidade, frases como essas são perigosas, quando não interpretadas. ${ }^{9}$

Citei esse trecho de Anders também para chamar atenção para um traço curioso na recepção brasileira desse livro. Os comentadores de Kafka celebram Pro \& Contra como se houvesse unicamente um Pro nesse livro, omitindo as suspeitas de peso enunciadas por Anders, suspeitas que prenunciam as críticas posteriores de um Lukács ao nilismo desesperado do escritor. Vale lembrar aqui que Anders começou seu estudo sobre Kafka em pleno nazismo, quando vivia exilado com Hannah Arendt (de quem ia se separar em breve) em Paris. Esclarece numa "nota preliminar" ao texto: "Este trabalho já existe há anos, pelo menos no que diz respeito às suas análises fundamentais: é o desenvolvimento de uma conferência, proferida no ano de 1934, no Institut d'Etudes Germaniques de Paris, sob o título de 'Teologia sem Deus'."10 Em outras palavras: em tempos de urgência e de miséria, em tempos de Not, a obra de Kafka provoca nos seus leitores mais engajados (Brecht, Anders ou Lukács) um mal-estar à altura de sua admiração. O caráter aporético de seus textos é percebido - diante de toda injustiça e dor a serem enfrentadas - como sendo um gesto ultrajante, ou, pior ainda, como um gesto de desistência e resignação, um compactuar com o inimigo.

Esse caráter aporético nos remete à questão da interpretação alegórica ou simbólica da obra de Kafka. Todos os intérpretes, mesmo os mais desconfiados, reconhecem que ela introduziu na literatura uma relação diferente das habituais configurações metafóricas, sejam elas lidas pela chave do símbolo ou da alegoria, uma outra relação entre imagem e sentido, se for lícito falar ainda dessa maneira. Depois de expressar suas suspeitas, Günther Anders observa, algumas páginas para a frente, que não se pode ler Kafka nem como escritor alegorista nem como simbólico, numa clara alusão crítica à interpretação simbólica forçada de Max Brod:

O alegorista põe em movimento seu mecanismo convencional (teológico, mitológico ou do gênero) de tradução ao substituir conceitos por imagens. O simbolista autêntico toma a parte pelo todo (partem pro toto), isto é, faz um objeto representar o outro, porque este, ao que se supõe, é da mesma substância que o outro. Kafka não faz nem uma coisa nem outra.[...] O fato de que a maior parte dos intérpretes, por aversão ao 'racionalismo frio' da alegoria, tenha se decidido por Kafka como 'simbolista', trai unicamente a preferência superficial pela 'profundidade', mas não a capacidade de produzir uma nova chave para um novo fenômeno (e a prosa de Kafka é um fenômeno novo).

O ponto de partida de Kafka não é uma crença comum, da qual nascem os símbolos, mas apenas a linguagem comum, pois esta fica à disposição dele - até dele, o rejeitado - em toda a sua amplitude e profundidade. Ela é inextorquível. Ele a partilha com o inimigo cortejado: o mundo. Mas ainda: ele colhe no acervo preexistente da linguagem, 
Não sabemos se Walter Benjamin escutou ou não essa conferência de Günther Anders em Paris. Ele retoma a questão da interpretação alegórica, questão que estudava já no capítulo central da Origem do drama barroco, onde aprofunda as premissas metafísicas da diferença entre alegoria e símbolo e reabilita a primeira como expressão privilegiada da arbitrariedade do sentido. Por ironia, Lukács deverá justamente retomar essa reabilitação de Benjamin para melhor fundamentar sua condenação do "niilismo das vanguardas", em particular em Kafka. ${ }^{12}$ Benjamin observa uma diferença essencial entre o alegórico do Barroco e a obra de Kafka: enquanto as alegorias barrocas desvalorizam os sentidos mundanos em oposição à inalterabilidade da Doutrina Sagrada, mesmo que esta seja inexprimível, as parábolas de Kafka se desdobram numa estranha autonomia de significação sem mais reenviar a uma doutrina preexistente. Cito a passagem chave da carta de W. Benjamin a Gershom Scholem de 12 de junho de 1938, uma carta contundente em sua crítica à recém-publicada biografia de Brod, mas que vai muito além dessa crítica conjuntural porque assinala a impossibilidade de qualquer interpretação totalizante, seja teológica, seja político-marxista, da literatura inaugurada pela obra de Kafka:

A obra de Kafka representa uma doença da tradição. Quis-se ocasionalmente definir a sabedoria como aspecto narrativo da verdade. Com isso a sabedoria é assinalada como um patrimônio da tradição; ela é a verdade em sua consistência hagádica. ${ }^{13}$

É esta consistência da verdade que se perdeu. Kafka estava longe de ser o primeiro a se defrontar com este fato. Muitos se adaptaram a ele aferrando-se à verdade ou àquilo que caso a caso consideravam como sendo ela; de coração pesado ou também mais leve renunciando à sua transmissibilidade. O genial propriamente dito em Kafka foi ter experimentado algo inteiramente novo: ele renunciou à verdade para se agarrar à transmissibilidade, ao elemento hagádico. As criações de Kafka são pela própria natureza parábolas. A miséria e a beleza delas, porém, é que tiveram que se tornar mais que parábolas. Elas não se deitam pura e simplesmente aos pés da doutrina, como a Hagada aos pés da Halachá. Uma vez deitadas elas levantam contra esta, inadvertidamente, uma pata de peso. ${ }^{14}$

Podemos fazer algumas observações a respeito dessa carta famosa, que retoma vários motivos do ensaio de Benjamin de 1934 sobre Kafka.

A primeira é que essa "doença da tradição" vem de longe: na literatura ocidental, inicia no mais tardar com o Dom Quixote. Nas análises de Benjamin, esse tema perdura desde o ensaio sobre "O narrador" até as várias versões da "Obra de arte na era de sua reprodutibilidade técnica". Essa doença caracteriza o que, com Max Weber, se chama de modernidade. Como "desencantamento do mundo", tal doença não pode ser curada por nenhum "retorno" utópico a uma realidade intacta, a um tipo tradicional, religioso ou patriarcal de organização social. Tal tentativa prepara muito mais o leito da regressão fascista e totalitária. Benjamin tenta apontar para outros caminhos possíveis, em particular o de transformar esses sintomas de doença em signos precursores de outro 
porvir, de uma outra relação à transmissão e à tradição, de uma outra relação à questão do sentido.

A segunda observação que deve ser feita é que, como se trata de uma nova relação, não podemos ainda defini-la. Nesse contexto de incerteza, o risco da desagregação e da perda de sentido é forte, como o indica na carta a comparação com a Halachá e a Hagadá. Tal comparação aponta para o núcleo essencialmente religioso, ou mesmo teológico, da noção de sentido. Como Nietzsche já o afirmou, acreditar num sentido claro, definitivo, fundamento último da linguagem humana, é uma transposição para uma figura epistemológica e linguística da fé num Deus absoluto.

Enfim, essa perda de sentido, ou melhor, essa perda do sentido, pode provocar várias reações paradoxais, mas que muitas vezes convivem juntas num mesmo sujeito. Se nasce uma grande nostalgia, uma melancolia incurável, também pode acontecer que surja uma impertinência alegre, uma certa leveza brincalhona como o realça o motivo dessas pequenas parábolas que, tais gatinhos, levantam suas patas contra a austeridade da doutrina.

Se a doença da tradição acarreta a impossibilidade de afirmação de um sentido eterno e universal, então as tentativas de interpretação simbólica de Kafka são falhas desde o início. Citando Benjamin, Adorno afirma essa impossibilidade e vê nela a origem da violência que os textos de Kafka exercem sobre seus leitores:

Se o conceito de símbolo tem alguma pertinência na estética, âmbito no qual ele é suspeito, ela se deve unicamente à afirmação de que os momentos de uma obra de arte remetem, em virtude da força que os conecta, para além deles mesmos: a totalidade dos momentos converge em um sentido. Nada, porém, seria mais inadequado no que diz respeito a Kafka. [...] Cada frase é literal, e cada frase significa. Esses dois aspectos não se misturam, como exigiria o símbolo, mas se distanciam um do outro, o ofuscante raio de fascinação surge do abismo que se abre entre ambos. Apesar do protesto de seu amigo ${ }^{15}$, a prosa de Kafka se alinha com os proscritos também para buscar antes a alegoria do que o símbolo. Benjamin a definiu com razão como parábola. Ela não se exprime pela expressão, mas pelo repúdio à expressão, pelo rompimento. É uma arte de parábolas para as quais a chave foi roubada; [...] Cada frase diz: 'interprete-me'; e nenhuma frase tolera a interpretação. Cada frase provoca a reação 'é assim', e então a pergunta: de onde conheço isso? O déjà vu é declarado em permanência. A violência com que Kafka reclama interpretação encurta a distância estética. ${ }^{16}$

A violência exercida por Kafka sobre seu leitor poderia ser descrita da seguinte forma: lendo seus textos, sentimos uma invencível vontade de interpretação que se reverte na impossibilidade de qualquer compreensão satisfatória; buscamos por um sentido, mas esse nos escapa, não porque remeteria a uma figura do sublime ou ao indizível do sagrado, mas porque a própria categoria de sentido revela sua insuficiência, uma espécie de trivialidade abissal que não explica mais nada. 
Como já dito, esse fenômeno pode ser registrado como uma perda infinita e deixar uma nostalgia incurável, ou, então, pode surtir um efeito menos melancólico, produzir uma irreverência alegre como se houvesse menos seriedade e menos peso em nossos ombros - e mais territórios desconhecidos a serem descobertos. Nostalgia e alegria talvez sejam inseparáveis. Nesse contexto, a conclusão da carta de Benjamin a Scholem é significativa:

É por isso que em Kafka não se pode mais falar em sabedoria. Sobram os produtos de sua desintegração. Há dois deles: um é o rumor das coisas verdadeiras (uma espécie de jornal-sussurro teológico que trata de coisas desacreditadas e obsoletas); o outro produto dessa diátese é a tolice [Torheit], que de fato dilapidou fundo o conteúdo próprio à sabedoria, mas em compensação guarda o lado agradável e sereno que foge sempre e em qualquer parte ao rumor. A tolice [Torheit] é a essência dos preferidos de Kafka do Dom Quixote, passando pelos ajudantes, até os animais. ${ }^{17}$

A figura do tolo, do Tor, não é somente aquilo que sobra dos grandes edifícios de construção do sentido universal, também é aquilo que pode apontar para outro devir. Pelo menos é nessa direção que proponho ler, para concluir esse pequeno ensaio, um dos contos mais enigmáticos de Kafka, "A preocupação do pai de família"18, que transcrevo a seguir:

Alguns dizem que a palavra Odradek deriva do eslavo e com base nisso procuram demonstrar a formação dela. Outros por sua vez entendem que deriva do alemão, tendo sido apenas influenciada pelo eslavo. Mas a incerteza das duas interpretações permite concluir, sem dúvida com justiça, que nenhuma delas procede, sobretudo porque não se pode descobrir através de nenhuma um sentido para a palavra.

Naturalmente ninguém se ocuparia de estudos como esse se de fato não existisse um ser que se chama Odradek. À primeira vista ele [es] tem o aspecto de um carretel de linha achatado e em forma de estrela, e com efeito parece também revestido de fios; de qualquer modo devem ser só pedaços de linha rebentados, velhos, atados uns aos outros, além de emaranhados e de tipo e cor os mais diversos. Não é contudo apenas um carretel, pois do centro da estrela sai uma varetinha e nela se encaixa uma outra, em ângulo reto. Com a ajuda desta última vareta de um lado e de um dos raios da estrela do outro, o conjunto é capaz de permanecer em pé como se estivesse sobre duas pernas.

Alguém poderia ficar tentando a acreditar que essa construção teria tido anteriormente alguma forma útil e que agora ela está apenas quebrada. Mas não parece ser este o caso; pelo menos não se encontra nenhum indício nesse sentido; em parte alguma podem ser vistas emendas ou rupturas assinalando algo dessa natureza; o todo na verdade se apresenta sem sentido, mas completo à sua maneira. Aliás não é possível dizer nada mais preciso a esse respeito, já que Odradek é extraordinariamente móvel e não se deixa capturar.

Ele [er] se detém alternadamente no sótão, na escadaria, nos corredores, no vestíbulo. Às vezes fica meses sem ser visto; com certeza mudou-se então para outras casas; depois porém volta infalivelmente à nossa casa. Às vezes, quando se sai pela porta e ele está inclinado sobre o corrimão logo embaixo, tem-se vontade de interpelá-lo. É natural que não se façam perguntas difíceis, mas sim que ele seja tratado - já o seu 
minúsculo tamanho induz a isso - como uma criança. 'Como você se chama?' perguntase a ele. 'Odradek', ele responde. 'E onde você mora?' 'Domicílio incerto', diz e ri; mas é um riso como só se pode emitir sem pulmões. Soa talvez como um farfalhar de folhas caídas. Em geral com isso a conversa termina. Aliás, mesmo essas respostas nem sempre podem ser obtidas; muitas vezes ele se conserva mudo por muito tempo como a madeira que parece ser.

Inutilmente eu me pergunto o que vai acontecer com ele. Será que ele pode morrer? Tudo o que morre teve antes uma espécie de meta, um tipo de atividade e nela se desgastou; não é assim com Odradek. Será então que a seu tempo ele ainda irá rolar escada abaixo diante dos pés dos meus filhos e dos filhos dos meus filhos, arrastando atrás de si os fios do carretel? Evidentemente ele não prejudica ninguém, mas a ideia de que ainda por cima ele deva me sobreviver me é quase dolorosa.

Esse pequeno texto claro e indecifrável suscitou várias interpretações, sendo que entre nós as mais conhecidas são as de Günther Anders e de Roberto Schwarz. Vou tentar esboçar uma leitura que resista às tentações de uma interpretação mais acabada.

É justamente dessa incompletude que trata o conto. O narrador - que se revela sendo o "pai de família" do título - não começa por sua opinião pessoal, mas pela evocação da tradição; evocação paradoxal e vaga porque as interpretações divergem: "alguns dizem...outros, por sua vez...ninguém se ocuparia de tais assuntos...alguém poderia ficar tentado a acreditar..." Na segunda parte do conto, quando Odradek será designado não mais como um objeto neutro (o pronome "es"), mas como um ser vivo ("er", pronome masculino), como o observa com precisão Roberto Schwarz ${ }^{19}$, passa-se da descrição daquilo que se diz a seu respeito à de seus usos e costumes; e, em seguida, a um curto diálogo entre um interlocutor impessoal ("se") e ele, para culminar no fim numa autointerrogação ansiosa do próprio narrador: "Inutilmente eu me pergunto...." ${ }^{20}$

O que se diz sobre Odradek, o que se transmite, qual é a tradição a seu respeito? Nada mais que opiniões divergentes e incertezas. Seu próprio nome suscita etimologias contrárias: uns o derivam do alemão, outros do eslavo (as duas línguas de Kafka). A falta de derivação e de origem segura induz à falta de sentido. Se nenhuma "dessas duas interpretações" é melhor que outra, então "permite-se concluir, sem dúvida com justiça, que nenhuma delas procede", conclusão reforçada pelo fato que "não se pode descobrir através de nenhuma um sentido para a palavra". Isto é, para existir, as palavras devem ter um sentido, pressuposto solapado pelo nome Odradek, que não tem origem nem sentido e que, no entanto, existe. ${ }^{21}$

Apesar da vaidade desses estudos etimológicos e interpretativos, eles prosseguem, afirma o narrador, porque existe "um ser que se chama Odradek". Outro pressuposto, portanto: estudar algo pressupõe que esse "algo" existe, pressuposto do qual é permitido duvidar, no mínimo na filosofia! Essa existência, porém, não configura ainda nenhum sentido. De fato, a descrição dos atributos físicos de Odradek confirma essa falta. Parece com um carretel revestido de fios, mas os fios somente são "pedaços de linha 
rebentados", portanto não servem para costurar nada, em particular, nenhum sentido. Ademais, esse carretel tem uma forma de estrela, uma estrela capenga, nenhuma estrela brilhante ou sagrada de Davi, uma estrela aleijada que consegue ficar de pé graças a um encaixe de varetinhas, umas pernas de "gambiara", diríamos no Brasil. Como seu nome não tem etimologia, assim também essa construção não tem origem histórica, é um "objeto órfão" (expressão de Philippe Artières), não se trata de restos de uma construção primeira, identificável, com utilidade e sentido, mas de resíduos ou de dejetos, de "refugos do mundo das aparências"22, sem que esses restos remetam a algo anterior a eles, mais consistente ontologicamente. É um resto sem antecedente e, nessa perspectiva, autossuficiente e atemporal: "O todo na verdade se apresenta sem sentido, mas completo à sua maneira", constata o narrador.

Esse ser sem origem nem sentido não se deixa "capturar", e ali notamos que Odradek não é somente um objeto neutro, mas um ser vivo, uma personagem com voz, fala, riso e, sobretudo, uma extraordinária mobilidade. O "pai de família", por sua vez, é muito mais sedentário e estável, já que se define pela posse da casa familiar: em alemão, o termo é "Hausvater", literalmente, o pai da casa. Ele encarna relações fixas ao espaço mora sempre na mesma casa - e ao tempo - tem filhos e deve ter tido um pai ele também. Relações estáveis que a mobilidade imprevisível e incontrolável de Odradek parece ameaçar, como se, por contraste, essa estabilidade se transformasse em sedentarismo insosso. "Odradek é o impossível da ordem burguesa", observa Roberto Schwarz. ${ }^{23}$ Odradek vai e vem com uma liberdade desconcertante e, como os bichos rasteiros e também as crianças, tem uma preferência clara por lugares de passagem: sótão, escadaria, corredores, vestíbulos, corrimão; não tem o quarto dele, mas usa o espaço da casa não tanto como moradia, antes mais como via de acesso a outros lugares. Responde à questão sobre seu lugar de moradia com uma expressão emprestada ao vocabulário burocrático-policial: "Unbestimmter Wohnsitz", ou "domicílio indeterminado", como um sem-teto ou sem residência fixa; a expressão ressalta o caráter ridículo da pergunta e o riso inorgânico, "sem pulmões", um "farfalhar de folhas caídas" acentua a derrisão (esse riso sem pulmões talvez seja um eco da tuberculose de Kafka).

Com efeito, as perguntas que the são feitas pelos adultos moradores bem comportados são mesmo risíveis, porque não perguntam sobre algo que não conhecem, numa verdadeira interrogação em comum, mas só reafirmam, através delas, a incapacidade de levá-lo em consideração. Já sabem seu nome, já sabem que não mora em nenhuma casa, só passa por todas, no entanto pergunta-se a ele como se chama e onde reside. Não são somente perguntas fáceis, porque endereçadas a um ser assimilado a uma criança, mas são, sobretudo, sinais do mal-estar mascarado pela condescendência do adulto, um pouco como se pergunta a um moribundo se não se sente melhor ou a uma criança o que ela quer ser mais tarde. Parece que o nomadismo lúdico e gratuito desse pequeno ser indefinível desestabiliza os adultos responsáveis, põe em xeque suas categorias dialógicas, sua necessidade de interpretação e de conclusão coerentes. 
Nesse texto tão avesso a qualquer leitura edipiana (em oposição à "Carta ao pai" ou ao "Veredicto"), o pai não tem a última palavra, aliás, tampouco o filho. Não há mais nem herança [Erbe] nem posse (nenhuma casa), nem história linear, nem filiação. Nesse momento, pela primeira vez, o narrador diz "eu", pois a estranha atemporalidade de Odradek relativiza, mais, ameaça a inscrição do pai de família no tempo, na transmissão intergeracional, na doação de uma moradia construída com esforço. Se Odradek não veio de nenhum lugar e não tem função no mundo dos pais de família, parece que o sentido da vida do narrador, de "minha" vida, desmorona diante de suas cambalhotas felizes. Não é mais o pai de família e narrador que faz perguntas, mas esse ser indefinido e indefinível questiona tanto o narrador quanto o leitor, sem por isso precisar elevar a voz.

Odradek nos convida, como toda a obra de Kafka, a um exercício muito distante de nossos estudos comparativos de literaturas nacionais, de nossas tentativas de interpretação coerente da tradição. Nos convida a uma literatura sem língua materna nem pátria, a um pensamento sem origem assegurada nem objetivo determinado, além das relações bem estabelecidas de propriedade e identidade. Um pensar irreverente, arriscado sem dúvida, brincalhão também, talvez um aprender a "rolar escada abaixo" sem se machucar, um andar menos reto e correto, um caminhar incerto sem a pretensão de saber aonde leva o caminho.

\footnotetext{
* Jeanne-Marie Gagnebin é professora titular do Departamento de Filosofia da PUC/SP.

* Esse texto retoma um ensaio publicado no livro Políticas e poéticas do inconformismo, Azougue Editorial, 2014, a partir de uma conferência na Universidade Federal de São Carlos no quadro do congresso organizado pelo Grupo de Estudos e Pesquisa Teoria crítica e Educação, em setembro de 2008. Agradeço aos organizadores do Livro, Paula Ramos de Oliveira e Renato Franco, e à Editora Azougue pela gentil disponibilização do texto para a Revista Viso.

1 Tomo a liberdade de remeter a meu artigo "Da dignidade ontológica da literatura". In: NASCIMENTO, F.; SALLES, W. (orgs.) Paul Ricoeur. Ética, identidade e reconhecimento. Rio de Janeiro: PUC-RIO, Loyola, 2013.

${ }^{2}$ BROD, M. Franz Kafka. Eine Biographie. Frankfurt am Main: Fischer, 1977, p. 129. Não há tradução para o português.

${ }^{3}$ Ibidem: "Vorgestern abends bei Max. Er wird immer fremder, mir war er es schon oft, nun werde ich es auch inm. 'Was habe ich mit Juden gemeinsam?' Ich habe kaum etwas mit mir gemeinsam und sollte mich ganz still, zufrieden damit, dass ich atmen kann, in einem Winkel stellen".

${ }^{4}$ Ibidem, p. 172.

5 "Die Kategorie der Heiligkeit (nicht etwa die der Literatur) ist überhaupt die einzige richtige, unter der Kafkas Leben und Schaffen betrachtet werden kann”. BROD, M. Op. cit., p. 50. Essa premissa é frontalmente atacada por W. Benjamin na sua carta a Scholem de 12 de junho de 1938.
}

${ }^{6}$ BENJAMIN, W.; SCHOLEM, G. Briefwechsel. Frankfurt am Main: Suhrkamp, 1980, pp. $266 \mathrm{ff}$.

${ }^{7}$ Nova tradução de Modesto Carone. São Paulo: Cosac Naify, 2007. 
8 "Assassinato de uma boneca de nome Franz Kafka". Essa resenha consta dos anexos da biografia de Brod.

${ }^{9}$ ANDERS, G. Op. cit., pp. 45-46. Podemos aqui observar que a citação do fragmento "Durante a construção da Muralha de China" omite o contexto no mínimo irônico dessas exortações, já que apesar de toda unidade proclamada, a muralha nunca chega a ser concluída, sendo muito mais uma cadeia de fragmentos esparsos que uma construção acabada.

${ }^{10}$ Ibidem, p. 10.

${ }^{11}$ Ibidem, pp. 56-57.

12 LUKÁCS, G. Realismo crítico hoje. Brasília: Editora de Brasília, 1969, p. 33 ff.

${ }^{13}$ Nota do tradutor Modesto Carone: "No original, hagadisch, adjetivo com o qual Walter Benjamin se refere à Hagadá, o mundo das lendas e narrativas que, na religião judaica, se distingue da Halachá, o mundo da doutrina ou da lei sagrada".

${ }^{14}$ BENJAMIN, W.; SCHOLEM, G. Op. cit, p. 272. Tradução de Modesto Carone na revista Novos Estudos Cebrap, n. 35 (mar. 1993), pp. 105-106.

${ }^{15}$ Provável alusão a Max Brod e à sua interpretação simbólica da obra de Kafka.

${ }^{16}$ ADORNO, T. W. Prismas. Rio de Janeiro: Ática, 1998, pp. 240-241.

${ }^{17}$ BENJAMIN, W.; SCHOLLER, G. Op. cit., p. 106.

${ }^{18}$ In KAFKA, F. Um médico rural. Tradução de Modesto Carone. São Paulo: Brasiliense, 1990, pp. 41-42.

${ }^{19}$ SCHWARZ, R. O pai de família e outros estudos. São Paulo: Paz e Terra, 1978, p. 23. Devemos aqui observar que é exatamente o processo inverso que acontece com o Gregor da Metamorfose: primeiro tratado como filho e irmão [er], ele é condenado à morte quando é tratado como mero objeto ou bicho [es] no fim.

${ }^{20}$ Ressaltado por mim, J. M. G.

${ }^{21}$ Wilhelm Emrich (Franz Kafka. Frankfurt am Main: Athenäum Verlag, 1965, p. 93) cita vários comentadores que tentaram encontrar etimologia e sentido desse nome a partir do radical rad-rat, conselho em alemão, e da negação od-, em tcheco, com o resultado que "Odradek" significaria o pequeno não conselho ou o pequeno não-conselheiro, o que poderia nos levar à teoria da narrativa como forma de conselho no parágrafo IV do "Narrador" de Walter Benjamin.

${ }^{22}$ Expressão de Freud citada por Adorno (Op. cit., p. 247) para caracterizar aos elementos da obra de Kafka.

${ }^{23}$ Op. cit. p. 24. 